\title{
PENGAMBILAN KEPUTUSAN KARIR PADA SEKOLAH MADRASAH ALIYAH AL-INAYAH BANDUNG BERDASARKAN PERBEDAAN JENIS KELAMIN
}

\author{
Pahri Siregar \\ Institut Agama Islam Negeri Padangsidimpuan, Sumatera Utara \\ pahrisiregar@upi.edu
}

\begin{abstract}
The purpose of this study was to determine the career decision-making of adolescents at Al-Inayah High School in Bandung based on gender differences. Research uses a quantitative approach with a survey method. The data measurement tool is a scale questionnaire developed by Vincent A. Haren, Ph.D based on indicators of Career Decision. The research participants were students of class X, XI and XII of the Aliyah Al-Inayah Bandung Madrasah School for Academic Year 2017/2018, which consisted of 104 participants consisting of 76 women and 28 men. Based on the results obtained, the average score of career decision making for male sex is higher than female sex. The average score of men is 2.96 while women score 2.92. There are significant differences in career decision making for male gender and female gender.

Keywords: Career Decision Making, Gender Differences
\end{abstract}

\begin{abstract}
Abstrak
Tujuan penelitian ini adalah mengetahui pengambilan keputusan karir remaja pada sekolah Menengah Atas Al-Inayah Bandung berdasarkan perbedaan jenis kelamin. Penelitian menggunakan pendekatan kuantitatif dengan metode survey. Alat pengukuran data adalah kuesioner berbentuk skala yang dikembangkan oleh Vincent A. Haren, Ph.D berdasarkan indikator pengambilan Keputusan Karir. Partisipan penelitian adalah peserta didik kelas X, XI dan XII Sekolah Madrasah Aliyah Al-Inayah Bandung Tahun Ajaran 2017/2018 yang berjumlah 104 peserta terdiri dari 76 perempuan dan 28 laki-laki. Berdasarkan hasil yang diperoleh bahwa skor rata-rata pengambilan keputusan karir jenis kelamin laki-laki lebih tinggi daripada jenis kelamin perempuan. Rata-rata skor laki-laki 2,96 sedangkan perempuan 2,92. Terdapat perbedaan yang signifikan pengambilan keputusan karir jenis kelamin laki-laki dan jenis kelamin perempuan.

Kata Kunci: Pengambilan Keputusan Karir, Perbedaan Jenis Kelamin
\end{abstract}




\section{PENDAHULUAN}

Selama beberapa dekade terakhir, perubahan pekerjaan menjadi semakin sering terjadi. Globalisasi, kemajuan teknologi yang cepat, pekerjaan yang kurang jelas, dan ketidakstabilan kerja meningkat (Duarte, 2004; Guichard \& Dumora, 2008). Teknologi yang berkembang pesat dan berubah telah menghilangkan beberapa kelompok pekerjaan tradisional dan menyebabkan eksistensi pekerjaan baru yang membutuhkan keahlian baru. Saat ini pemilihan karir menjadi masalah yang sangat penting, karena mempengaruhi seluruh kehidupan individu, penting untuk diselidiki semua faktor yang mempengaruhi pengambilan keputusan karir ini (Bandura et al. 2001).

Tren penelitian baru-baru ini berfokus pada perluasan kerangka kerja SCCT dari karir formasi pilihan untuk proses pengambilan keputusan karir (Jin et al., 2009; Rogers et al., 2008). Lebih khusus lagi, sejumlah peneliti telah mengeksplorasi peran kepercayaan diri dengan hubungannya dengan pengambilan Keputusan karir, seperti kepribadian, dan Variabel proses pembentukan karier, misalnya komitmen karir (Jin et al., 2009; Wang et al., 2006) perencanaan dan eksplorasi karir (Rogers et al., 2008). Pilihan karir merupakan salah satu hal penting dalam kehidupan individu (Uthayakumar, Schimmack, Hartung, \& Rogers, 2010). Pilihan karir memiliki banyak implikasi bagi individu. Pengambilan keputusan karir dipengaruhi tempat tinggal dan pekerjaan individu (Masumba, Yanhong, \& James, 2009), sebagian orang mulai menyadari pentingnya proses pengambilan keputusan karir, sehingga banyak orang mencari konselor karir untuk bimbingan profesional atau meminta bantuan pengambilan keputusan kepada yang ahli (Gati, Saka, \& Krausz, 2001; Sagiv, 1999 Konselor karir dan pembantu pengambilan keputusan karir biasanya melibatkan penilaian awal- karakteristik individu yang terkait dengan karir (Campbell, 2000; Mastie, 1994). Berbagai Instrumen telah dikembangkan untuk menilai perbedaan individu yang terkait dengan keputusan karir (Harren, 1979; Phillips \& Pazienza, 1988; Whitfield, Feller, \& Wood, 2009).

Keputusan karir tampaknya menjadi pikiran yang sulit bagi seseorang, karena diyakini memberi dampak signifikan pada kehidupan seseorang. Pengembangan identitas karir merupakan tugas penting dalam kemunculan masa dewasa individu mengeksplorasi tujuan hidup mereka (Arnett, 2004). Kegagalan untuk mengembangkan identitas karir telah dikaitkan dengan berbagai indikator penyesuaian negatif, seperti tingkat kebahagiaan rendah dan kepuasan rendah hidup (Hirschi, 2009; Strauser, Lustig, \& Çiftci, 2008). Beberapa para ahli teori telah berhipotesis bahwa keberhasilan pencapaian keputusan karir membutuhkan individu untuk melalui serangkaian kegiatan proses pengambilan keputusan karir (misalnya, Gati \& Asyer, 2001; Harren, 1979; Van Esbroeck, Tibo, \& Zaman, 2005). Salah satu cara untuk mengatasi kesulitan dalam pengambilan keputusan karir dengan cara mencari bantuan/pertolongan.

Remaja di kelas X, XI dan XII baik laki-laki atau perempuan difahami situasi yang tepat untuk memahami pengambilan keputusan karir. Harrington \& Harrigan (2006) menyimpulkan bahwa di kelas XI dan kelas XII, remaja mulai 
objektif terhadap pekerjaan / profesi dan menjadi lebih realistis, dibandingkan dengan siswa kelas VIII sampai kelas X. Beberapa penulis percaya bahwa keraguraguan pengambilan keputusan karir terjadi akibat ketidakmampuan membuat keputusan dalam konteks dan situasi yang berbeda (Frost \& Pertunjukan, 1993; Gaffner \& Hazler, 2002; Patalano \& Wengrovitz, 2006 Saka \& Gati, 2007). Peneliti dalam pengambilan keputusan karir menyimpulkan bahwa pengambilan keputusan karir dapat dikaitkan dengan faktor budaya, adat dan jenis kelamin (Fouad, 1993; Gati, Krausz, \& Osipow, 1996). Keputusan individu adalah hasil sampingan dari hubungan antara ciri-ciri psikologis individu, rasa nilainya terhadap pekerjaan, dan alternatifnya. Itu juga dipengaruhi oleh lamanya pelatihan, tingkat ketergantungan, dan jenis hubungan dengan orang (Gati, Osipol, \& Givon, 1995; Tak \& Lee, 2003). Oleh karena itu, pengambilan keputusan karir secara langsung dipengaruhi oleh budaya seseorang dan kekhususan sosial. Tujuan yang ingin dicapai melalui penelitian ini adalah mengetahui pengambilan keputusan karir berdasarkan perbedaan jenis kelamin.

Pengambilan keputusan karir salah satu elemen fundamental dari seseorang yang bisa mengatur regulasi diri/managerial. Skorikov (2007) mengemukakan bahwa faktor utama yang mempengaruhi persiapan karir termasuk keputusan karir adalah kepercayaan diri, harga diri, dan adaptasi sosial. Model ini menempatkan konsep kepercayaan diri Bandura (1986) di garis depan variabel yang terkait dengan keputusan membuat karir. Model ini menjelaskan bahwa pengambilan keputusan karir merupakan fungsi dari kepercayaan individu dan jika model ini dijalankan, ada kemungkinan keberhasilan yang baik (yaitu, hasil harapan). Kedua aspek ini, kepercayaan diri dan cita-cita bergantung pada perspektif masa depan.

Selanjutnya, Tang, Pan dan Newmeyer (2008) berpendapat bahwa, dalam pengambilan keputusan karir, sangat penting ada kepercayaan diri. Chuang dan Dellmann-Jenkins (2010) mencatat bahwa, dibandingkan dengan para siswa yang tidak masuk magang di luar kampus, mereka yang masuk memiliki awal yang lebih awal dalam jalur karir mereka dan menetapkan tujuan yang lebih tinggi, terutama karena mereka memiliki lebih banyak pengetahuan dan informasi mengenai industri yang mereka rencanakan masukkan, yang meningkatkan keefektifan diri mereka. Taksonomi terdiri dari tiga kelompok kesulitan utama, terbagi dalam 10 kategori kesulitan spesifik.

Kluster pertama, Kurangnya Kesiapan, termasuk tiga kategori kesulitan yang mungkin timbul sebelum proses karir pengambilan keputusan: (1) kurangnya motivasi, (2) ketidaktegasan umum, dan (3) disfungsional keyakinan. Kelompok kedua dan ketiga termasuk kategori kesulitan itu mungkin timbul selama proses pengambilan keputusan karir. Cluster utama kedua meliputi empat kategori, melibatkan Kurangnya Informasi tentang: (4) proses pengambilan keputusan karir, (5) diri, (6) pekerjaan, dan (7) cara memperoleh informasi tambahan. Kluster Ketiga meliputi tiga kategori, melibatkan tidak memperoleh informasi yang konsisten (8) informasi tidak dapat diandalkan, (9) konflik internal, dan (10) konflik eksternal. .Penyediaan informasi, dukungan emosional 
dan dukungan finansial, dan dengan mempromosikan harapan karir yang sesuai dengan gender, agama, atau budaya individu.

Selanjutnya, magang diyakini memberi kesempatan kepada mahasiswa memilih universitas yang memadai. Selain magang, dalam pengambilan keputusan dipengaruhi cara/gaya berpikir seseorang. Sebagaimana Savickas, (2005) menyatakan fase awal dari pertumbuhan pemilihan keputusan karir remaja dipengaruhi dukungan orang tua dan pentingnya seseorang memiliki kemampuan beradaptasi karir. Dukungan orang tua didefinisikan sebagai bantuan yang diberikan oleh pengasuh utama kepada individu dalam bentuk pemberian bantuan instrumental orang tua, pemodelan terkait karir, dorongan verbal, dan dukungan emosional (Turner \& Lapan, 2002). Perlu optimisme dalam pengambilan keputusan karir, dengan optimism membuat seseorang semakin percaya diri dalam pengambilan keputusannya. Optimisme karir didefinisikan sebagai kecenderungan individu untuk "mengharapkan hasil terbaik atau untuk menekankan yang paling positif aspek pengembangan karir masa depan seseorang" (Rottinghaus et al., 2005, hal. 11 ). Sementara optimisme karir berhubungan positif dengan harapan kerja, sebuah keadaan motivasi positif yang memungkinkan individu memperoleh perasaan nyaman, sesuai jalur, dan tujuan situasi kerja (Juntunen \& Wettersten, 2006). Ditetapkan bahwa mereka secara konseptual dan empiris berbeda satu sama lain (Juntunen \& Wettersten, 2006 ).

\section{METODE PENELITIAN}

Pendekatan yang digunakan adalah pendekatan kuantitatif dengan metode deskriptif jenis survei. Metode deskriptif bertujuan untuk membuat deskripsi, gambaran atau lukisan secara sistematis, faktual dan akurat mengenai fakta-fakta, sifat-sifat serta hubungan antar fenomena yang diselidiki. Partisipan penelitian adalah peserta didik kelas X, XI dan XII Sekolah Madrasah Al-Inayah Bandung tahun ajaran 2017/2018 yang berjumalah 104 peserta terdiri dari 74 perempuan dan 28 laki-laki Pengumpulan data penelitian menggunakan instrumen berupa kuesioner skala pengambilan keputusan karir. Analisis data penelitian dilakukan secara kuantitatif, yaitu dengan menghitung persentasi tingkat pengambilan keputusan kari. Adapun untuk mengetahui perbedaan antara pengambilan keputusan karir perempuan dan laki-laki dilakukan uji beda dua rata-rata dengan menggunakan uji $t$.

\section{HASIL DAN PEMBAHASAN}

Deskripsi hasil penelitian penjelaskan tentang gambaran pengambilan keputusan karir, berikut disajikan gambaran awal pengambilan keputusan kariipeserta didik secara umum. Hasil rekapitulasi kategorisasi tingkat perilaku

prososial peserta didik Kelas X, XI dan XII Madrasah Aliyah Al-Inayah Bandung Tahun Ajaran 2017-2018 yang dijadikan sampel penelitian adalah sebagai berikut.

Tabel 1

\section{Gambaran Awal Pengambilan keputusan karir}




\begin{tabular}{|c|c|c|c|}
\hline Kategorisasi & Interval & $\begin{array}{c}\text { Jumlah Peserta } \\
\text { Didik }\end{array}$ & Persentase \\
\hline Tinggi & $67<\mathrm{X} \leq 88$ & 38 & 37 \\
\hline Sedang & $45<\mathrm{X} \leq 66$ & 66 & 63 \\
\hline Rendah & $22<\mathrm{X} \leq 44$ & 0 & 0 \\
\hline \multicolumn{2}{|c|}{ Jumlah } & $\mathbf{1 0 4}$ & $\mathbf{1 0 0}$ \\
\hline
\end{tabular}

Berdasarkan tabel di atas, dapat diketahui tingkat pengambilan keputusan karir berada pada kategori tingkat sedang, yaitu dari 104 peserta yang dijadikan sampel dalam penelitian, sebanyak $63 \%$ (66 peserta) termasuk dalam kategori sedang. Adapun kategori tinggi sebanyak $37 \%$ (38 peserta), sedangkan hasil rendah $0 \%$.

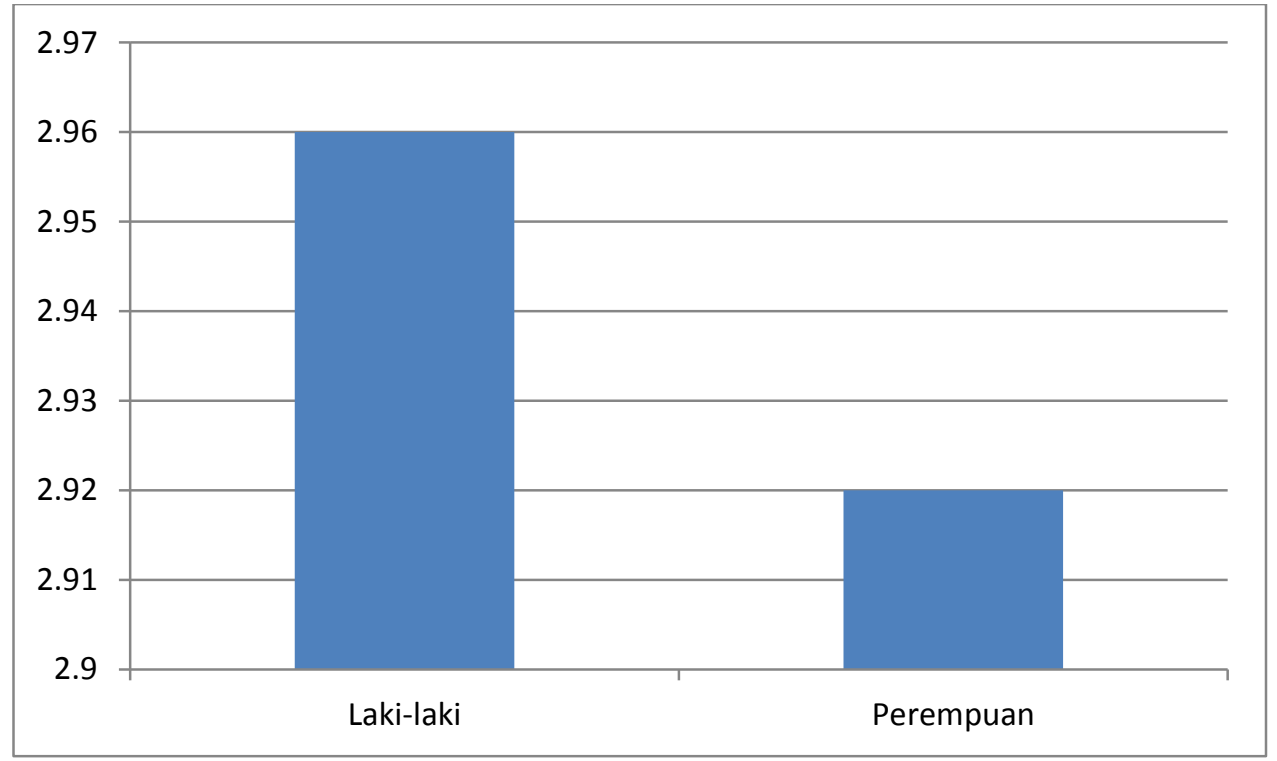

Grafik 1. Gambaran Pengambilan keputusan karir Berdasarkan Jenis Kelamin

Dari hasil uji beda pengambilan keputusan karir peserta perempuan dan peserta laki-laki terdapat perbedaan yang signifikan dengan nilai 0,514 >0,05, artinya terdapat perbedaan yang signifikan antara pengambilan keputusan karir laki-laki dan perempuan. Secara umum berdasarkan hasil yang didapat bahwa skor rata-rata pengambilan keputusan karir kelompok laki-laki cenderung lebih tinggi daripada kelompok perempuan. Rata-rata skor laki-laki 2,96 sedangkan 
perempuan 2,92. Jika dilihat dari signifikansi pada pengambilan keputusan karir peserta laki-laki dan peserta perempuan terdapat perbedaan yang signifikan. Banyak peneliti dalam pengambilan keputusan karir menyimpulkan bahwa pengambilan keputusan karir dapat dikaitkan dengan factor budaya(Fouad, 1993; Gati, Krausz, \& Osipow, 1996). Faktor budaya bisa meliputi suku, agam ras, adat dan jenis kelamin. Pengambilan keputusan karir dipengaruhi hubungan antar individu dalam keluarga. Oleh karena itu, pengambilan keputusan karir secara langsung dipengaruhi oleh budaya seseorang dan kekhususan sosial. Pengambilan keputusan berlaku untuk keputusan mengenai peluang karir dan tujuan karir. Eksplorasi karir menyangkut sejauh mana seorang individu mengeksplorasi peluang dan memiliki kepercayaan diri walaupun pilihan yang berbeda dari teman sebaya. Kepercayaan diri dalam pengambilan keputusan karir didefinisikan sebagai penilaian orang tentang kemampuan mereka untuk mengatur, merencanakan, dan melakukan tindakan yang diperlukan untuk mencapai tujuan masing-masing atau untuk mereka berhasil dan mencapai tingkat kinerja tertentu (misalnya, Bandura, 1977).

Peran motivasi tidak secara eksplisit dinyatakan dalam teori-teori ini. Misalnya, motivasi diajukan sebagai prasyarat untuk pengambilan keputusan karir di kognitif Gati, Krausz, dan Osipow (1996) taksonomi kesulitan membuat keputusan karir, namun peran dan sifatnya tidak dijelaskan secara jelas. Dalam teori karir kognitif sosial (Prapaskah, Brown, \& Hackett, 1994), motivasi sebagian dijelaskan oleh proses evaluatif diri yang mendasari ekspektasi hasil, namun konsepnya Motivasi tidak secara khusus ditujukan. Akhirnya, teori desain-hidup (Savickas, 2001) memang mampu menjadi motivasi peran penting dalam masalah karir klien, namun teori ini tidak secara eksplisit disebutkan peran yang dimainkan oleh faktor motivasional dalam pengembangan karir.

Pengembangan identitas adalah kunci untuk memahami transisi yang berlangsung dari masa remaja hingga awal masa dewasa, di mana kaum muda berada tertantang untuk mengembangkan identitas mereka dalam berbagai domain kehidupan, termasuk karir, ideologi, dan keterlibatan romantis ( Arnett, 2000; Erikson, 1968 ). Secara khusus, telah ditemukan tingkat karir yang lebih tinggi pengambilan keputusan self-efficacy berhubungan dengan tingkat yang lebih rendah dari keraguan karir (misalnya, Creed et al, 2004;. Gati et al, 2011;. Nota et al., 2007), keyakinan karir yang lebih adaptif ( Luzzo \& Day 1999), Kurang takut komitmen karir ( Betz \& Serling 1993 ), dan lebih besar ketekunan dalam studi akademis ( Peterson, 1993 ).

\section{SIMPULAN}

Berdasarkan hasil penelitian dan pembahasan mengenai pengambilan keputusan karir berdasarkan jenis kelamin kelas X, XI dan XII Madrasah Al-Inayah Bandung terdapat perbedaan signifikan. Arah penelitian memberikan kontribusi dalam layanan bimbingan dan konseling diantaranya meningkatkan penelitianpenelitian yang berhubungan dengan pengambilan keputusan karir berdasarkan jenis kelamin, ras, asal, sekolah dan sebagainya. 


\section{DAFTAR PUSTAKA}

Al-Kalbania, Muna Saif \& Amala Salleh (2010), Developing a Career Decision Making Indicator (CDMI) Procedia Social and Behavioral Sciences 5 (2010) 2146-2153 doi:10.1016/j.sbspro.2010.07.428

Anuradha J. Bakshi, (2011) Past adolescence, into and across adulthood: career crises and major decisions Int J Educ Vocat Guidance (2011) 11:139-153 DOI 10.1007/s10775-011-9197-0

Cordeiro, Pedro M. dkk (2015) Cognitive-motivational antecedents of career decision-making processes in Portuguese high school students: A longitudinal study Journal of Vocational Behavior http://dx.doi.org/10.1016/j.jvb.2015.08.005

Creed, Peter A. dkk (2009), Career decision-making, career barriers and occupational aspirations in Chinese adolescents Int J Educ Vocat Guidance (2009) 9:189-203 DOI 10.1007/s10775-009-9165-0

Criana, Claudia \& Sebastian Turdab (2015), The connection between the level of career indecision and the perceived self-efficacy on the career decisionmaking among teenagers Procedia - Social and Behavioral Sciences 209 ( 2015 ) 154 - 160 doi: 10.1016/j.sbspro.2015.11.271

Di Fabio, Annamaria \& Letizia Palazzeschi (2009) Emotional intelligence, personality traits and career decision difficultiesInt J Educ Vocat Guidance (2009) 9:135-146 DOI 10.1007/s10775-009-9162-3

Di Fabio, Annamaria dkk (2014), The Role of Personality in the Career DecisionMaking Difficulties of Italian Young Adults Journal of Career Assessment DOI: $10.1177 / 1069072714535031$

Ebner, Katharina (2016) Validation of the German Career Decision-Making Profile An Updated 12-Factor Version Journal of Career Assessment 1-26 DOI: $10.1177 / 1069072716679996$

Eranova, Mariya \& Shameen Prashantham (2016), Decision making and paradox: Why study China? European Management Journal http://dx.doi.org/10.1016/j.emj.2016.03.002

Fadaei Nasab Mojgan, dkk, (2012) The Relation of Career Indecision and Parental Attachment among Iranian Undergraduate Students Int J Adv Counselling (2013) 35:251-260 DOI 10.1007/s10447-012-9180-6

Fouziah Mohd, dkk (2010). The Influence of Contextual Aspects on Career Decision Making of Malaysian Technical Students Procedia Social and Behavioral Sciences doi:10.1016/j.sbspro.2010.10.050 
Gati, Itamar (2013), Preparing young veterans for civilian life: The effects of a workshop on career decision-making difficulties and self-efficacyJournal of Vocational Behavior http://dx.doi.org/10.1016/j.jvb.2013.06.001

Gati, Itamar and Nimrod Levin (2012), The Stability and Structure of Career Decision-Making Profiles: A 1-Year Follow-Up Journal of Career Assessment DOI: 10.1177/1069072712448892

Guan, Miya dkk (2016) The role of traditionality in the relationships among parental support, career decision-making self-efficacy and career adaptability Journal of Vocational Behavior doi: 10.1016/j.jvb.2016.02.018

Hui Xu, dkk (2015). Career Decision Ambiguity Tolerance Scale: Construction and initial validations Journal of Vocational Behavior http://dx.doi.org/10.1016/j.jvb.2015.01.006

Jenni Sipila (2017). The influence of word-of-mouth on attitudinal ambivalence during the higher education decision-making process Journal of Business Research http://dx.doi.org/10.1016/j.jbusres.2017.07.014

Jiang, Zhou dkk (2015), Career Decision Self-Efficacy and Life Satisfaction in China: An Empirical Analysis Soc Indic Res DOI 10.1007/s11205-0151201-5

Jieqiong. F (2016).The Role of Thinking Styles in Career Decision-making Selfefficacy among University Students.Thinking Skills and Creativity http://dx.doi.org/10.1016/j.tsc.2016.03.001

Jonas Gabrielsson, dkk (2009). Career motives and entrepreneurial decisionmaking: examining preferences for causal and effectual logics in the early stage of new venturesSpringer Science+Business Media, DOI 10.1007/s11187-009-9217-3

Jonas Lindahl, dkk (2016). The information value of early career productivity in mathematics: a ROC analysis of prediction errors in bibliometricly informed decision makingSpringerlink.comDOI 10.1007/s11192-0162097-9

Jung, Heajung dkk(2015) Future time perspective and career decisions: The moderating

Jung, Heajung dkk, (2015). Future time perspective and career decisions: The moderating effects of affect spin Journal of Vocational Behavior http://dx.doi.org/10.1016/j.jvb.2015.04.010

Koumoundourou, A. Georgia (2010), Career Decision-Making Difficulties: The Mediating Role of Core Self-Evaluations Journal of Career Assessment published online 29 December 2010 DOI: 10.1177/1069072710385547

Koumoundourou, dkk (2012) Career Decision Self-Efficacy, and Vocational Identity

Krieshok, Thomas S. dkk (2009) Career decision making: The limits of rationality and the abundance of non-conscious processes Journal of Vocational Behavior doi:10.1016/j.jvb.2009.04.006

Kvitkovičová, L. dkk (2017) Roles of Attachment Relationships in Emerging Adults' Career Decision-Making Process:A Two-Year Longitudinal 
Research Design Journal of Vocational Behaviordoi: 10.1016/j.jvb.2017.05.006

Kyung-Nyun, (2012). KimTrajectories of female student's career decision between high school and college: organizationally separate but developmentally linkedEducation Research Institute, Seoul National University, Seoul, Korea 2012DOI 10.1007/s12564-012-9217-x

Lent, Robert W. dkk, (2015). Applying the social cognitive model of career selfmanagement to career exploration and decision-making Journal of Vocational Behavior http://dx.doi.org/10.1016/j.jvb.2015.12.007

Lia M. Daniels, dkk, (2011). Relieving career anxiety and indecision: the role of undergraduate students' perceived control and faculty affiliations Soc Psychol Educ (2011) 14:409-426 DOI 10.1007/s11218-010-9151-x

M.Patrick Raymund James Garcia dkk (2015) Career optimism: The roles of contextual support and career decision-making self-efficacy Elsevier Inc. All rights reserved http://dx.doi.org/10.1016/j.jvb.2015.02.004

Mihaela Guranda, (2014). The Importance of Adult's Personality Traits and Professional Interests in Career Decision Making Procedia - Social and Behavioral Sciences doi: 10.1016/j.sbspro.2014.05.368

Neslihan Bolat \& Hatice Odac (2016), High School Final Year Students' Career Decision-Making Self-Efficacy, Attachment Styles and Gender Role Orientations Curr Psychol DOI 10.1007/s12144-016-9409-3

Neureiter, Mirjam dkk (2016). Two sides of the career resources coin: Career adaptability resources and theimpostor phenomenon, Journal of Vocational Behavior (2016), doi:10.1016/j.jvb.2016.10.002

Nguyen Huong Lien, dkk, (2017). Family decision-making in an emerging market: Tensions with tradition Journal of Business Research http://dx.doi.org/10.1016/j.jbusres.2017.09.003

Pedro M. Cordeiro, (2015). Cognitive-motivational antecedents of career decision-making processes in Portuguese high school students:A longitudinal study Journal of Vocational Behavior http://dx.doi.org/10.1016/j.jvb.2015.08.005

S Laurent (2014). Parenting styles and career decision-making among French and Korean adolescents Elsevier Inc. All rights reserved. http://dx.doi.org/10.1016/j.jvb.2014.02.002 0001-8791

Simon, dkk (2017). Career decision self-efficacy plays a crucial role in hospitality undergraduates' internship efficacy and career preparation, Published by Elsevier Ltd. http://dx.doi.org/10.1016/j.jhlste.2017.08.002

Stavros Theofanis, dkk (2011). Pappas Career decision making of Greek post secondary vocational students: the impact of parents and career decision making selfefficacy Procedia Social and Behavioral Sciences doi:10.1016/j.sbspro.2011.04.310

Torok, Reka dkk (2016). Analyzing Models of Career Decision Self-Efficacy: FirstOrder, Hierarchical, and Bifactor Models of the Career Decision Self- 
Efficacy Scale. Springer Science+Business Media New York 2016 DOI 10.1007/s12144-016-9464-9

Vertsberger, Dana (2015) The effectiveness of sources of support in career decision-making: A two-year follow-up Journal of Vocational Behavior http://dx.doi.org/10.1016/j.jvb.2015.06.004

Walker Terrance L. dkk, (2012). The role of future time perspective in career decision-making. Elsevier Inc. All rights reserved doi:10.1016/j.jvb.2012.06.002

William MacAskill, (2013). Replaceability, Career Choice, and Making a DifferenceEthic Theory Moral Prac DOI 10.1007/s10677-013-9433-4

Wilner T (2015). Career decision-making profiles and career decision-making difficulties: A cross-cultural comparison among US, Israeli and Chinese samples Elsevier Inc. All rights reserved http://dx.doi.org/10.1016/j.jvb.2015.03.007

$\mathrm{Xu} \mathrm{Li,} \mathrm{dkk} \mathrm{(2014).} \mathrm{The} \mathrm{influence} \mathrm{of} \mathrm{social} \mathrm{comparison} \mathrm{on} \mathrm{career} \mathrm{decision-making:}$ Vocational identity as a moderator and regret as a mediator Journal of Vocational Behavior http://dx.doi.org/10.1016/j.jvb.2014.10.003 